\title{
Product flexibility in selecting manufacturing planning and control strategy
}

\author{
EMINE PERSENTILI† and SEMA E. ALPTEKIN:*
}

The manufacturing systems capable of producing several products simultaneously are frequently subject to changes in product types due to demand fluctuations. In such systems a product flexible manufacturing planning and control (MPC) strategy is needed to change from one product type to another with minimum deterioration to system performance levels. The objective of this research is to develop a systematic analysis and evaluation approach in order to compare the MR P-push and JIT-pull strategies quantitatively based on a product flexibility measure. A new product flexibility measure is developed based on the sensitivity to change concept and presented together with the implementation in a real manufacturing system. Simulation is used to compare the performance of a JIT-pull with an MRP-push strategy based on performance measures, e.g. manufacturing lead time, work-in-process inventory, backorders, machine utilization and throughput. The performances of the two strategies are evaluated in two scenarios: (i) a single product; (ii) a second product is added (the first product being simple and the second being complex in terms of processing). The impacts of adding the second product on the performance measures for the push and pull strategies are then assessed. A multi-attribute evaluation scheme is used to compare the two strategies where the attribute values are the change in performance measures as the second product is added. The proposed product flexibility measure is utilized in the interpretation of the results.

\section{Introduction}

Today's manufacturing environment can be characterized by intensified competition, rapid market changes, increased product variety and short product life cycles. In order to be competitive, manufacturing enterprises need to respond rapidly to product demand changes. Flexibility, as a measure of manufacturing performance, has become recognized as very significant due to the changing market, and the need to produce greater variety with the same facilities. Flexibility is defined as a function of the physical attributes of the manufacturing system. Therefore, the majority of the related research is based on the hardware requirements of flexibility with little concern for the system planning and control mechanisms that are necessary for its realization (Benjaafar and Ramakrihnan 1993). Flexibility should be the concern of the entire organization. It can support a firm's business strategies as a competitive weapon at the strategic level, take a hedging role against environmental uncertainties at the tactical level, and help to maintain smooth production flow at the operational level (Hyun and Ahn 1992). Flexibility cannot just be bought by means of machinUSA.

$\dagger$ Engineering Management Department, University of Missouri-R olla, R olla, MO 65401,

\$Industrial and Manufacturing Engineering Department, Cal Poly, San Luis Obispo, CA 93407, USA.

* To whom correspondence should be addressed. e-mail: salpteki@calpoly.edu 
ery, but must be carefully planned and managed (Jaikumar 1986). Machine level flexibility alone is not sufficient to ensure a competitive edge. The added advantage of flexibility in the planning and control of the system must be present. There is an increasing recognition in today's manufacturing environment of the need for more flexible manufacturing planning and control (MPC) strategies that are capable of responding to rapid changes in product demand.

MPC is primarily concerned with the efficient and effective management of material flow and resource utilization consistent with management objectives, within time constraints and with the uncertainties derived from sources external or internal to the manufacturing system. An effective MPC strategy can provide a substantial competitive advantage for a company through the synchronization of the activities at the planning and operational levels. Concerns about manufacturing competitiveness drive an interest in the development of alternative MPC strategies. The most commonly used strategies in industry are material requirements planning (MRP)-push and just-in-time (JIT)-pull strategies. The execution of the basic MPC functions shows some variation under these different strategies. The differences between MRP-push and JIT-pull approaches make them appropriate strategies for different manufacturing environments.

Our objective is to choose the MPC strategy which manages the change in the system performance measures, due to the product type variation, with minimum deterioration or maximum improvement. This type of flexibility is referred to as product flexibility and is defined as the capability to change the current product mix at a low cost in a short period, with the same machines and fixtures (Gupta and Goyal 1992, Chryssolouris and Lee 1992). The considered uncertainty in the manufacturing environment is the changing demand which is an external disturbance of the system. The product flexible strategy used to coordinate the MPC functions of a manufacturing system will vary with the nature of the production process, business environment, customer expectations and the needs of management. Because of its complexity, a systematic approach for decision making is needed to consider all tradeoffs underlying the selection of a flexible MPC strategy in a changing manufacturing environment.

The assessment and comparative analysis of MPC strategies has received much attention in the literature. The behaviour of the strategies under uncertainties is investigated in order to make realistic approximations in planning, and suggest precautionary actions to account for the uncertainties (Murthy and Ma 1991, Miltenburg and Wijngaard 1991). There are several studies which conceptually compare the operating logic of the MPC strategies (Fandel and Francois 1988, Karmarkar 1989, Deleersnyder et al. 1992). In the major model-based comparative studies, simulation is recognized as the most powerful tool in analysing the MPC systems because of their inherent complexities (Krajewski et al. 1987, Spearman and Zazanis 1992). Uncertainties resulting from internal disturbances (hardware-related factors which are caused by failures in machines, tools, material handling systems and computer systems) and external disturbances (factors which are not hardware related, e.g. changes in product mix, personnel, demand quantity and operating policies) existing in a manufacturing environment are incorporated in simulation models (Sarker and Jfitzsimmons 1989). The significance of these system variables on the success of MPC systems has been analysed (Krajewski et al. 1987, Sipper and Shapira 1989, Rees et al. 1989, Sumichrast et al. 1992, Chu and Shih 1992). Although there are several measures considered as the basis of analyses, there is no research 
investigating a combination of several system performance measures in order to observe their joint effects. Flexibility, as a performance evaluation measure in comparative analysis of MPC strategies, is considered by only a few researchers in the conceptual-based evaluation (Wainwright et al. 1993, Galbraith et al. 1993) and in a quantitative evaluation based on a complex mathematical model (Muramatsu et al. 1985). There is no research encountered on the systematic comparison of push and pull control strategies based on flexibility in a real manufacturing system.

On the other hand, there is a vast amount of research on the definition, measurement and use of flexibility. Many researchers have defined several types of flexibility according to its relationship to the different types of disturbances or uncertainties that the system has to cope with. In order to form a basis for the development of flexibility measures, manufacturing flexibility types are classified according to their impacts on long-term and short-term decisions (Bernardo and Mohamed 1992). Flexibility is defined as the ability of a system or decision process to cope with changing circumstances; therefore, it is evaluated by its success to cope with change or equivalently by the loss that the change incurs on the system (Buzacott 1982). Many quantitative measures are proposed in the literature for manufacturing flexibility in order to aid in decision making (Gustavsson 1984, Kumar 1986, Barad and Sipper 1988, Brill and Mandelbaum 1989, Ramasesh and Jayakumar 1991, Gupta and Somers 1992, Gaimon and Singhal 1992), however, there is no consensus on a generic manufacturing flexibility measure. The major approaches encountered in the use of flexibility are discussed in terms of the relation between flexibility and performance measures, and the impacts of various decisions on flexibility. The majority of the decisions considered in these studies are the selection of the flexibility level in a manufacturing system and the evaluation of different system configurations, investment decisions, loading decisions, product mix, part routing and scheduling decisions based on different flexibility types (Ghosh and Gaimon 1992, Roll et al. 1992). In studies dedicated to the quantification of product flexibility, typical measures proposed are: the number of possible product types that can be produced in a manufacturing system (Jaikumar 1986, Das and Nagendra 1993); ratio of total output to setup costs; and time and cost to change from one product type to another (Browne et al. 1988). All of the proposed measures have drawbacks, e.g. requiring numerous types of data and being impractical for implementation in realistic manufacturing systems. Moreover, there is no research encountered in the literature which focuses on the utilization of a practical measure in comparing the flexibility of MPC strategies to varying product types produced in the system.

The intention of this research is to develop a systematic analysis and evaluation approach in order to compare the MR P-push and JIT-pull strategies quantitatively based on a product flexibility measure. In the rest of this paper, the comparative analysis and a new product flexibility measure that is proposed by the authors are presented together with the implementation in a real manufacturing system.

\section{Comparative analysis: modelling and evaluation}

The modelling and analysis of MPC strategies requires an understanding of the characteristics imposed by the different strategies on material, information and control interactions generated in the manufacturing and delivery of products. In the MR P-push system, the schedule pushes material forward based on average planned usage rather than the actual usage of material. Orders are launched and pushed 
through the system to meet some established due dates. The order is moved to the next workstation upon completion, with the expectation that the receiving workstation needs it. The pull logic embodied in the JIT-pull system focuses on the manufacturing process from the perspective of the finished item. In a pull system, orders are placed at the end item level and work is pulled through the facility to satisfy the demand of the end item. The order is not moved to the next workstation until it is needed or demanded by that station. Ordering is triggered by actual usage rather than planned usage.

The evaluation of the strategies is performed through the analysis of system performance measures from the simulation results. The simulation models for MRP-push and JIT-pull strategies are built representing the same real manufacturing system operating under the special characteristics of the respective strategies. The real manufacturing system under consideration is producing several types of plastic window frames and can be characterized as a multistage, multiproduct, intermittent manufacturing system, which is frequently subject to change from one product type to another. The system consists of machines that are capable of performing more than one operation on more than one part type with negligible setup time and cost when switching between different parts or operations. The process structure, prepared to be independent to product type, is illustrated in figure 1.

In the manufacturing system, the production routing is similar for all window types, however, the processes exhibit some differences in each production stage according to the type of window (e.g. W1, W2, ..). The products are processed in fixed processing times. The set of product types that the system is capable of producing is known, and their required operations and routings are entered into the system. The production is performed mainly in eight stages including cutting, mounting, milling, welding and assembly processes (e.g. ST1, ST2, .., ST8) for the components of windows manufactured (e.g. P, PF, PM, PS, F, M and S). The evaluation of the strategies begins on the simulation models which emulate the manufacturing system satisfying only one type of product demand. In the following stage of evaluation, a second type of product is added to the models. The alterations in the system performance levels are observed as a result of an increase in workload and process variability due to adding the second product type to the system. Among the product types manufactured in the system, two types are chosen to be modelled. The selection of product types is achieved by modelling the production of two widely different products in order to observe system disturbances clearly due to the addition of a second product. The ability to distinguish the product types produced in the system depends on their sizes and structures. Size dictates the number and

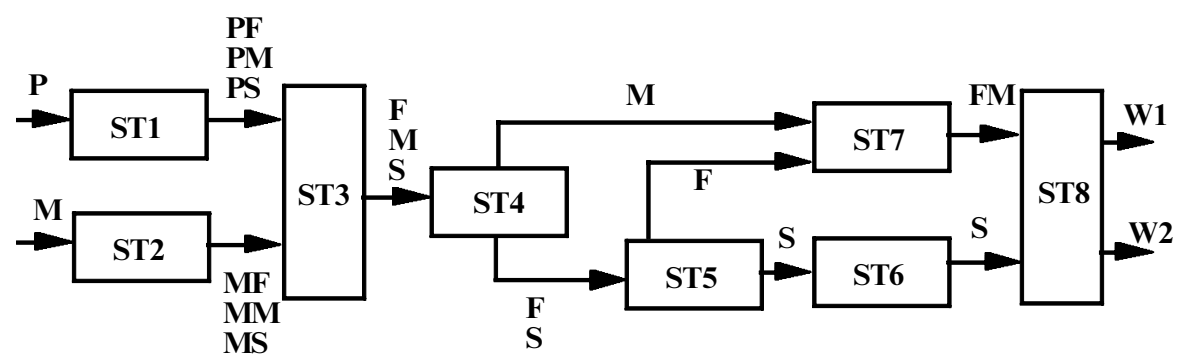

Figure 1. Process structure. 
dimensions of components required for the manufacture of an end product. On the other hand, structure dictates the complexity of the assembly and processes required in manufacturing an end product. The first product is chosen as small and simple, and the second one is chosen as large and complex.

The common input parameters in both of the models are the number of products, transfer batch sizes, lead times and priorities of product types. The parameters, which are different for the MR P-push and JIT-pull models, are the order schedules of components and the inventory levels. The evaluation of the two models is based on the major system performance measures. The conditions defined by management on the major performance measures are as follows.

- Average work-in-process (WIP), average backorder, average manufacturing lead time should not increase.

- Total production time should not increase.

- Throughput value at the end of the planning horizon not to be less than the planned amount.

- Machine utilization at each production stage should not decrease.

These are the ultimate conditions which are impossible to attain while changing the product types produced in real manufacturing systems. Therefore, the attainable objective is to have a minimum deterioration or a maximum improvement in the system performance levels during a product change. The results of the simulation models for MR P-push and JIT-pull systems with one product (W1) and two products (W1, W2) along with the observed differences in the performance measures are shown in table 1.

The results in table 1 are interpreted based on the MPC strategy which performs best with respect to the addition of the second product type in the system. When only

\begin{tabular}{|c|c|c|c|c|c|c|}
\hline & \multicolumn{3}{|c|}{ MR P-push model } & \multicolumn{3}{|c|}{ JIT-pull model } \\
\hline & W1 & $\mathrm{W} 1, \mathrm{~W} 2$ & $\%$ & $\mathrm{~W} 1$ & $\mathrm{~W} 1, \mathrm{~W} 2$ & $\%$ \\
\hline WIP & 67.0 & 148.0 & 120.9 & 41.1 & 66.0 & 60.6 \\
\hline $\mathrm{B} / \mathrm{O}$ & 0 & 28.4 & 2840.0 & 0 & 8.2 & 820.0 \\
\hline THPUT & 252.0 & 167.0 & -33.7 & 252.0 & 210.0 & -16.7 \\
\hline $\mathrm{LT}(\mathrm{W} 1)$ & 7.7 & 33.8 & 337.3 & 3.5 & 12.3 & 256.8 \\
\hline LT (W2) & - & 9.9 & - & - & 12.2 & - \\
\hline $\mathrm{T}$ & 45.0 & 57.0 & 26.7 & 45.0 & 54.0 & 20.0 \\
\hline $\mathrm{U}(\mathrm{ST} 1)$ & 21.0 & 29.0 & 38.1 & 21.0 & 28.9 & 37.8 \\
\hline $\mathrm{U}(\mathrm{ST} 2)$ & 21.0 & 29.0 & 38.1 & 21.0 & 28.9 & 37.8 \\
\hline $\mathrm{U}(\mathrm{ST} 3)$ & 38.9 & 58.2 & 49.5 & 38.9 & 57.2 & 46.9 \\
\hline $\mathrm{U}(\mathrm{ST} 4)$ & 14.8 & 25.4 & 72.4 & 14.8 & 24.4 & 65.6 \\
\hline U(ST5) & 32.7 & 39.7 & 21.4 & 32.7 & 36.2 & 10.7 \\
\hline $\mathrm{U}(\mathrm{ST6})$ & 14.0 & 38.6 & 175.0 & 27.2 & 39.9 & 46.5 \\
\hline U(ST7) & 23.3 & 33.3 & 42.9 & 23.3 & 28.9 & 23.8 \\
\hline U(ST8) & 85.0 & 97.0 & 14.2 & 93.4 & 97.9 & 4.9 \\
\hline
\end{tabular}

WIP, average WIP level (\# of parts); B/O, average backorder level (\# of products); LT, average manufacturing lead time (hours); THPUT, throughput (\# of products), produced in the planning horizon; $\mathrm{T}$, total production time (hours) required to produce the planned amount; $\mathrm{U}$, utilization of each workstation $(\%)$.

Table 1. Results of MRP-push and JIT-pull models. 
one product type is produced in the system, throughput values and total production times for both strategies are the same as the planned amounts and the planned schedules, therefore, the average backorder levels are 0. Although the total number of products scheduled for each period with one product and with two product types are taken as equal, the addition of the second product type decreases the amount produced in the regular planning period in the MR P-push model by 34\% and in the JIT-pull model by $17 \%$, which results as backorders in the two-product model. The results show that the WIP level change is $121 \%$ in the MR P-push model and $61 \%$ in the JIT-pull model. The average lead time of the first product type in both of the JIT-pull models is shorter than for the MR P-push models, however, the lead time of the second product type is shorter in the MRP-push model. One reason for this result is the higher priority assigned to $\mathrm{W} 2$ than $\mathrm{W} 1$ in batch size production of the MRP-push model. Another reason is that the mixed-model production is applied in the JIT-pull model, which forces both products to be produced every hour. The utilization figures are almost the same in the one-product models of both MRP-push and JIT-pull systems; the only difference is in workstations ST6 and ST8. Workstation ST8 is the bottleneck station in the system. As compared to the others, workstations ST6 and ST8 have higher utilization in the one-product JITpull model because they monitor the pulling mechanism with their production rate. When the second product type is added to the system, the utilization figures are higher for the MRP-push model in the stations with the high variety of processes.

If in the comparison of the two MPC strategies, one strategy shows less deterioration and greater improvement in the system measure than the other, then selection of the optimum flexible strategy is straightforward. However, in most cases, changes in all of the performance measures do not all favour one strategy or the other. Therefore, a unification of measures based on their relative importance for a particular manufacturing system is required. The unification of performance measures is driven by overall management objectives and the business environment. Such an evaluation method is developed and presented in the rest of the paper.

\section{Quantification of product flexibility}

In the product flexibility measurement approaches reviewed to date, flexibility is considered as an intrinsic attribute of manufacturing systems. A more generic measure, which is relatively easy to apply to realistic manufacturing situations, is proposed by Chryssolouris and Lee (1992), where product flexibility is considered as a relative attribute that depends not only on the manufacturing system itself, but also on the external demands placed upon it. This measure is developed based on the premise that the flexibility of a manufacturing system is determined by its sensitivity to change, which means that the lower the sensitivity the higher the flexibility. Because flexibility is inversely related to the sensitivity to change (STC), a measure of flexibility must quantify the STC. The original formulation of STC has two components, which are the penalty for change and the probability of change. The definition of STC is made in the general form as:

$$
\mathrm{STC}=\text { penalty } \times \text { probability } .
$$

In the approach of Chryssolouris and Lee (1992), the question concerning product flexibility is as follows. How flexible a manufacturing system should be acquired now in order to accommodate product changes in the future? This question addresses future demand for changes, which can not be predicted with certainty. 
Demand for change, stated in probabilistic terms to deal with prediction uncertainty, is therefore accounted for in the STC. The critical part of calculating STC is the estimation of the relevant penalties and probabilities. The relevant penalties are the costs of modifying the manufacturing system to produce future products, which includes the cost of required machinery and system modifications. Estimation of these costs requires an assessment of the degree of design change between a current product and future products. The probability is viewed as the estimation of the possibility of demand for a future product type and the probability of deciding in favour of producing this type. The measure of original STC is formally defined as:

$$
\mathrm{STC}=\operatorname{Pn}\left(X_{i}\right) \operatorname{Pr}\left(X_{i}\right), \quad i=1, \ldots, n,
$$

where $n=$ the number of potential changes; $i=$ the change or state transition index; $X_{i}=i$-th potential change; $\operatorname{Pn}\left(X_{i}\right)=$ the penalty of $i$-th potential change; $\operatorname{Pr}\left(X_{i}\right)=$ the probability of $i$-th potential change.

Thus, STC can be interpreted in the original formula as the expected value of the penalty to be incurred by the system for potential changes. The calculation of STC is viewed as an application of single-attribute decision-making under uncertainty, where the variables are the states of nature. In a comparison of a number of manufacturing system alternatives which can be utilized for producing future product types, the alternative with the lowest STC value would be preferred.

In our research, the STC concept is used; however, its components and general form are modified, because the question concerning product flexibility is considered as follows: 'How flexible a MPC strategy should be applied in the existing manufacturing system in order to accommodate existing product changes at a low cost?' Changing demand is an external disturbance for both approaches, however, the original approach considers it as an uncertainty in the manufacturing environment. We investigate the impact of changing demand in the existing system; therefore, we assume that there is a demand for the existing product types and it is changing between different product types. As a result of this assumption, the probability component in the original STC definition has the value of 1 , therefore it can be excluded from the formula. In the original approach, the penalties of changing product types are considered as the costs of modifying the manufacturing system to produce new products. The penalty of changing product types is measured as the total cost incurred in the manufacturing system in terms of deterioration in system performance levels. For example, an increase in work-in-process (WIP) inventory levels results in an increase in manufacturing cost. The calculation of corresponding cost figures resulting in the manufacturing system by the alteration of each system performance measure is very complicated. Hence, multi-attribute decision analysis is implemented where penalties caused by alterations in major system performance levels are considered as attributes. Management's preferences of importance in system performance measures are considered for unifying different attributes and making the strategy selection decision consistent with management objectives and manufacturing system specifications. The STC definition is modified as follows:

$$
\mathrm{STC}=\operatorname{Pn}\left(X_{i}\right)=w_{j} X_{j}, \quad i=1, \ldots, n ; j=1, \ldots, m,
$$

where $m=$ the number of system performance measures considered; $j=$ the system performance measure index; $w_{j}=$ weight of importance given by management for the performance measure $j ; X_{j}=$ evaluated alteration in the level of performance 
measure $j$ as a result of change in the system state (adding or substituting a product type in the manufacturing system creates another system state).

In the comparison of MPC strategies, the alternative with the lowest STC value would be preferred. If a change in the product mix can be implemented in the system without altering the system performance levels, then the MPC strategy provides maximum flexibility in the system and STC is zero. If, on the other hand, change results in a large alteration, the MPC strategy results in inflexibility in the system and STC is large. This STC definition is implemented for the real manufacturing system under consideration. The state- 1 is the system state with one product type (W1), and the state-2 is the system state with two product types (W1, W2). The change in the system state alters all major system performance measures for both MR P-push and JIT-pull strategy alternatives.

The STC value is calculated based on the weighted index method of multi-attribute decision analysis. The value of each attribute is given as a percentage of alteration in each performance measure. The evaluation of each attribute is performed using a reference value, which is the maximum value of each attribute, which helps avoid dominance of attributes that are measured in small units. For the attributes of WIP, backorder, lead time, production duration and throughput, the evaluation rating is considered on a scale of 0 to 10 (lowest to highest linearly) which corresponds to possible attribute values from no deterioration to maximum deterioration. On the other hand, there is an improvement in the utilization attribute due to the change in system state and the evaluation rating is considered on a scale of 0 to 10 (highest to lowest linearly) which corresponds to possible attribute values from maximum improvement to no improvement in utilization. The computed evaluation ratings of attributes are shown in table 2.

The relative importance of each performance measure, which is defined as a weight factor in the STC definition, varies in different manufacturing systems. In

\begin{tabular}{lcrcc}
\hline & Weight & $\begin{array}{r}\text { Norm. } \\
\text { weight }\end{array}$ & $\begin{array}{c}\text { MRP-push } \\
\text { eval. rat. }\end{array}$ & $\begin{array}{c}\text { JIT-pull } \\
\text { eval. rat. }\end{array}$ \\
\hline WIP & 50 & 7.0 & 9.67 & 4.85 \\
B/O & 70 & 10.1 & 10.00 & 2.93 \\
THPUT & 70 & 10.1 & 9.64 & 4.76 \\
LT (W1) & 90 & 13.0 & 9.64 & 7.34 \\
LT (W2) & 100 & 14.5 & 6.60 & 8.13 \\
T & 60 & 8.7 & 8.89 & 6.67 \\
U(ST1) & 30 & 4.4 & 7.82 & 7.84 \\
U(ST2) & 30 & 4.4 & 7.82 & 7.84 \\
U(ST3) & 30 & 4.4 & 7.17 & 6.32 \\
U(ST4) & 30 & 5.4 & 5.86 & 9.39 \\
U(ST5) & 40 & 4.4 & 8.78 & 8.34 \\
U(ST6) & 30 & 4.4 & 0.00 & 9.64 \\
U(ST7) & 30 & 4.4 & 7.55 & \\
U(ST8) & 30 & 100.0 & 9.19 & \\
Total & 690 & $5 / 4$ & & \\
\hline
\end{tabular}

WIP, average WIP level (\# of parts); B/O, average backorder level (\# of products); LT, average manufacturing lead time (hours); THPUT, throughput (\# of products), produced in the planning horizon; $\mathrm{T}$, total production time (hours) required to produce the planned amount; $\mathrm{U}$, utilization of each workstation $(\%)$.

Table 2. Weights and evaluation ratings of attributes. 
this particular system, the management ranked the attributes in the order of decreasing preference, based on the requirements and specifications of the manufacturing company under consideration and the management's perception regarding the relative importance of each measure. In this particular system, lead time is considered the most important attribute. The production duration has the second preference and the third preference is a tie between the backorder attribute and the throughput attribute. The WIP attribute is the fourth highest in preference and utilization has the lowest. Between the product types, the lead time of the complex product has a higher preference than the simple product. Among the workstations, station 5 has the highest preference because of the expensive machinery used in the process, with all other stations having the same preference. As a result of these specifications, the ranking of attributes can be shown as follows (the symbol ' $>$ ' means 'is preferred to' and ' $=$ ' means 'is equally preferred to'):

$$
\begin{aligned}
\mathrm{LT}(\mathrm{W} 2)>\mathrm{LT}(\mathrm{W} 1)>\mathrm{T}>\mathrm{B} / \mathrm{O}=\mathrm{THPUT}>\mathrm{WIP}>\mathrm{U}(\mathrm{ST} 5)>\mathrm{U}(\mathrm{ST} 1) \\
=\mathrm{U}(\mathrm{ST} 2)=\mathrm{U}(\mathrm{ST} 3)=\mathrm{U}(\mathrm{ST} 4)=\mathrm{U}(\mathrm{ST} 6)=\mathrm{U}(\mathrm{ST} 7)=\mathrm{U}(\mathrm{ST} 8) .
\end{aligned}
$$

Hereafter, weights are assigned to attributes according to their ranks in order to quantify the relative importance of each attribute. The weights and their normalized values are also shown in table 2. The weighted evaluation of each alternative is calculated by multiplying the attribute evaluation ratings (out of 10) and normalizing them. The STC value is calculated as 81.63 for the MR P-push strategy and 67.80 for the JIT-pull strategy. The results show that, for the manufacturing system under consideration with the given attribute ratings, the MRP-push strategy is more sensitive than the JIT-pull strategy to change in product types. In other words, the JITpull strategy is more product-flexible than the MR P-push strategy.

The ranking of attributes is very significant in the results, therefore with a different attribute ranking the results could be considerably different. The ranking of attributes is modified based on the assumption that the system has expensive machinery and that high equipment utilization is of prime importance, then the following representation of ranking is obtained:

$$
\begin{gathered}
\mathrm{U}(\mathrm{ST} 5)>\mathrm{U}(\mathrm{ST} 1)=\mathrm{U}(\mathrm{ST} 2)=\mathrm{U}(\mathrm{ST} 3)=\mathrm{U}(\mathrm{ST} 4)=\mathrm{U}(\mathrm{ST} 6)=\mathrm{U}(\mathrm{ST} 7) \\
=\mathrm{U}(\mathrm{ST} 8)>\mathrm{LT}(\mathrm{W} 2)>\mathrm{LT}(\mathrm{W} 1)>\mathrm{T}>\mathrm{B} / \mathrm{O}>\mathrm{THPUT}>\mathrm{WIP} .
\end{gathered}
$$

The weighted evaluation values are calculated as 73.80 for the MRP-push strategy and 73.36 for the JIT-pull strategy, nearly the same product flexibility level for both strategies. From this analysis, it is apparent that management objectives and manufacturing system specifications determine, to a large extent, the decision on selecting a strategy that offers product flexibility.

\section{Conclusions and further research}

The motivation of this study is to support the MPC strategy selection process in manufacturing systems that encounter rapid changes in product types manufactured. A product-flexible MPC strategy allows changes in product mix with a minimum lost in the system performance levels. A systematic method is developed and implemented for the comparative analysis of MRP-push and JIT-pull strategies in a real manufacturing system. The comparison is made on the basis of simulation results wherein the two strategies are compared for one-type and two-type product systems. The responses of the strategies to change in the product type are measured and 
interpreted utilizing the product flexibility quantification approach which is developed based on the sensitivity to change concept. The JIT-pull strategy is chosen as the product flexible strategy for the particular manufacturing system under consideration.

For future research, the approach developed for quantification of product flexibility might be used with slight modifications for other flexibility types, e.g. for routing, machine and operation flexibility. To extend this approach to other applications, the definition of state change could be modified due to the type of flexibility. Deterioration in each performance indicator means additional cost for the system, and improvement means profit. If cost figures corresponding to alterations in each performance level can be estimated, quantification of the product flexibility can be performed directly based on cost values instead of evaluation rating values and weights of the attributes. In order to perform planning and control functions consistent with a changing manufacturing environment, there is a need for new measures that quantify the flexibility of systems.

\section{References}

BARAD, M. and SIPPER, D., 1988, Flexibility in manufacturing systems: definitions and Petri net modeling. International Journal of Production Research, 26, 237-248.

BENJAAFAR, S. and RAMAKRIHNAN, R ., 1993, The effect of routing and machine flexibility on performance of manufacturing systems. In Proceedings of the 2nd Industrial Engineering Research Conference, pp. 445-450.

BERNARDO, J. J . and MOHAMED, Z., 1992, The measurement and use of operational flexibility in the loading of flexible manufacturing systems. European Journal of Operational Research, 60, 144-155.

Brill, P. H. and Mandelbaum, M., 1989, On measures of flexibility in manufacturing systems. International Journal of Production Research, 27, 745-756.

Browne, J., Harhen, J. and Shivnan, J., 1988, Production Management Systems: A CIM Perspective (Wokingham, UK: Addison-Wesley).

BuZACOTT, J. A., 1982, The fundamental principles of flexibility in manufacturing systems. In Proceedings of the 1st International Conference on FMS, pp. 13-22.

ChryssolourIs, and LEe, M., 1992, An assessment of flexibility in manufacturing systems. Manufacturing Review, 5, 105-116.

Chu, C. H. and SHIH, W. L., 1992, Simulation studies in JIT production. International Journal of Production Research, 30, 2573-2506.

DAS, S. K. and NAGENDRA, P., 1993, Investigations into the impact of flexibility on manufacturing performance. International Journal of Production Research, 33, 2337-2354.

Deleersnyder, J. L., Hodgson, T. J., King, R. E., O'Grady, P. J. and SAVva, A., 1992, Integrating kanban type pull systems and MRP type push systems: insight from a Markovian model. IIE Transactions, 24, 43-56.

FANDEL, G. and FRANCOIS, P., 1988, Rational material flow planning with MRP and kanban. Essays on Production Theory and Planning (Berlin: Springer).

Gaimon, C. and Singhal, V., 1992, Flexibility and the choice of manufacturing facilities under short product life cycles. European Journal of Operational Research, 60, 211-223.

Galbraith, L., Miller, W. A. and SuRESH, S., 1993, Identifications of metrics and transition functions of pull system implementation. Computer Integrated Manufacturing Systems, 6, $117-124$.

Ghosh, S. and GAImON, C., 1992, Routing flexibility and production scheduling in a flexible manufacturing system. European Journal of Operational Research, 60, 344-364.

GuPTA, Y. P. and GL, S., 1992, Flexibility trade-offs in a random flexible manufacturing system: a simulation study. International Journal of Production Research, 30, 527-557.

GuptA, Y. P. and SOMERS, T. M., 1992, The measurement of manufacturing flexibility. European Journal of Operational Research, 60, 166-182.

Gustavsson, S. O., 1984, Flexibility and productivity in complex production processes. International Journal of Production Research, 22, 801-808. 
HyUn, J. H. and AHN, B. H., 1992, A unifying framework for manufacturing flexibility. Manufacturing Review, 5, 251-260.

J AIKUMAR, R ., 1986, Postindustrial manufacturing. Harvard Business Review, 64, 69-76.

KARMARKAR, U., 1989, Getting control of just-in time. Harvard Business Review, 122-131.

KRAJEW SKi, L. J., King, B. E., RitZMAN, L. P. and Wong, D. S., 1987, Kanban, MR P, and shaping the manufacturing environment. Management Science, 33, 39-57.

KUMAR, V., 1986, On measurement of flexibility in flexible manufacturing systems: an information-theoric approach. In Proceedings of the Second ORSA/TIMS Conference on Flexible Manufacturing Systems: Operations Research Models and Applications, pp. 131-143.

Miltenburg, J . and WijngaARD, J., 1991, Designing and phasing in just-in-time production systems. International Journal of Production Research, 29, 115-131.

Muramatsu, R., ISHII, K. and TAKAHASHI, K., 1985, Some ways to increase flexibility in manufacturing systems. International Journal of Production Economics, 23, 691-703.

Murthy, D. N.P. and MA, L., 1991, MRP with uncertainty: a review and some extensions. International Journal of Production Economics, 25, 51-64.

R AMASESH, R. V. AND J AYAKUMAR, M. D ., 1991, Measurement of manufacturing flexibility: a value based approach. Journal of Operations Management, 10, 446-468.

REES, L. P., HUANG, P. Y . and TAYLOR, B. W., 1989, A comparative analysis of an MRP lotfor-lot system and a kanban system for a multistage production operation. International Journal of Production Research, 27, 1427-1443.

Roll, Y., KARNI, R. and ARZI, Y., 1992, Measurement of processing flexibility in flexible manufacturing cells. Journal of Manufacturing Systems, 11, 258-268.

SARKER, B. R. and JFITZSIMMONS, A., 1989, The performance of push and pull systems: a simulation and comparative study. International Journal of Production Research, 27, 1715-1731.

SIPPER, D. and SHAPIRA, R., 1989, JIT vs. WIPa trade-off analysis. International Journal of Production Research, 27, 903-914.

SPEARMAN, M.L. and ZaZANis, M. A., 1992, Push and pull production systems: issues and comparisons. Operations Research, 40, 521-532.

Sumichrast, R. T., RusSell, R. S. and TAYLOR, B. W., 1992, A comparative analysis of sequencing procedures for mixed-model assembly lines in a just-in-time production system. International Journal of Production Research, 30, 199-214.

WAinwright, C. E. R., HARRISON, D. K. and LEONARD, R., 1993, Production control strategies within multi-product batch manufacturing companies. International Journal of Production Research, 31, 365-380. 